\title{
Tim Elfrink and Gus Garcia-Roberts: Blood Sport: Alex Rodriguez, Biogenesis, and the Quest to End Baseball's Steroid Era
}

\author{
Penguin Group LLC, New York, 2014, 480 pp., ISBN 978-0-525-95463-7, \\ Paperback, \$12.75
}

\author{
Ryan $\operatorname{Kota}^{1}$ (1)
}

Published online: 5 May 2015

(C) T.M.C. Asser Instituut 2015

Blood Sport: Alex Rodriguez, Biogenesis, and the Quest to End Baseball's Steroid Era, co-authored by Miami New Times managing editor Tim Elfrink-who single-handedly broke the first narrative on Biogenesis-and Newsweek investigative reporter Gus Garcia-Roberts, tells the story of professional sports' largest war on the use of banned and illegal substances and the subsequent monumental crackdown. A novel piece centred on years of closed-door relations, strategic leaks, and ill-advised money exchanges, it comes as no surprise that the central theme throughout Blood Sport is that of corruption at the highest level.

Bud Selig-former Commissioner of Major League Baseball-is recognised as the individual who brought the steroid (Biogenesis) era to an end. This message will undoubtedly reign supreme when historians gloss over the legacy of this hard-nosed commissioner. But is it fully warranted? The authors of Blood Sport - a seminal book postBiogenesis - choose not to disagree with this probability — or answer the question for that matter; instead, they present an objective view and let the readers judge for themselves.

Elfrink and Garcia-Roberts create an informational timeline with each succeeding section giving rise to a new chapter of deceit, secrecy, and illegal behaviour. But do not be fooled; as much as Major League Baseball would like for the public to view them as the white knight in this saga, those associated with the production and distribution of steroids are not the only party with blood on their hands.

Corruption-the central theme in this chronological masterpiece on the rise and eventual eradication of steroids

Ryan Kota

rwk14@my.fsu.edu

1 Florida State University, 101 Chieftain Way, Tallahassee, FL 32306, USA in baseball-does not discriminate. The information presented by the authors depicts an organisation - the MLBthat was ready to fight fire with fire; again showing how professional sport is 'above the law'. "If the theft of the Biogenesis records was not random, it sets up a simple calculus. Dan Mullin, on behalf of the MLB and with the approval of at least baseball executive Manfred, purchased the records from tanning club regular Gary Jones. If Jones was behind the theft of the records, a straight line implicates MLB as buying stolen property that was bound for state investigation" (p. 374).

For Commissioner Selig, no distance is too far. When asked about the amount of money spent on unravelling the Biogenesis scandal, Chief Operating Officer Rob Manfred could not come up with an exact number; not even a ballpark figure (no pun intended), but noted that it was "a substantial expenditure" (p. 384).

Was this 'substantial expenditure' of millions of dollars worth it to stop Biogenesis? Was it worth it to spend millions to suspend 15 professional baseball players? Are lost wages-or "the 2 percent steroid tax" (p. 387)anything more than a slap on the wrist for these professional athletes? Who came out of this situation with the dirtiest hands? The concluding thoughts in Blood Sport raise these questions, among others.

It is yet to be seen where baseball will be in the coming years. But knowing where it has been, what it has been through, and the steps taken to get to our current position, Elfrink and Garcia-Roberts close with an ominous statement that perfectly sums up the current state of the MLB, modified to recognise the current Commissioner of Major League Baseball.

Selig's war might be over, but there will be plenty more wars in Rob Manfred's future. I for one wish you luck sir. 